\title{
Applying 1D Sediment Models to Reservoir Flushing Studies: Measuring, Monitoring, and Modeling the Spencer Dam Sediment Flush with HEC-RAS
}

by Paul Boyd and Stanford Gibson

PURPOSE: The purposes of this Coastal and Hydraulics Engineering Technical Note (CHETN) are (1) to summarize the effort to model a real-time reservoir flush with the U.S. Army Corps of Engineers (USACE), Hydrologic Engineering Center (HEC), River Analysis System (HEC-RAS), and (2) to determine the model's applicability for flushing applications. HEC-RAS is a onedimensional (1D) numerical hydraulics and sediment model. Reservoir flushing events generally have no historic precedent, so they cannot be calibrated. If HEC-RAS performs well on a carefully measured reservoir flushing event, it can be applied to other reservoir flushing studies with greater confidence.

BACKGROUND: Sedimentation reduces the usable space in Federal reservoirs and depletes downstream reaches of ecologically important substrates. The USACE and other Federal agencies are considering passive management approaches like flushing and routing to manage reservoir sediment. In the last 3 years, HEC developed new analysis tools for these alternatives. The USACE Missouri River Districts applied these new tools to flushing studies by the Omaha District (NWO) (Lewis and Clark Lake [Gavins Point Dam] on the Missouri River) and to routing studies by the Kansas City District (Tuttle Creek Reservoir, a tributary of the Kansas River) (Gibson and Boyd 2014; Davis et al. 2014; Shelley and Gibson 2015). However, because these reservoir management strategies are still rare in the United States, these results have not been compared to prototype data.

Because the USACE has never operated reservoirs for these passive, alternative sediment management objectives, these models are uncelebrated and therefore, somewhat speculative. One of the problems with modeling flushing alternatives is that novel management options cannot be tested against analogous historical scenarios. Modeling, calibrating, and validating sediment transport features in HEC-RAS to an actual flushing data set would significantly increase confidence and reduce uncertainty in future models developed in HEC-RAS.

The Niobrara River (Figure 1) is the primary sediment source into Lewis and Clark Lake, the smallest and most downstream reservoir on the Missouri River Main Stem System. Niobrara River loads are the most sensitive and uncertain parameter in Lewis and Clark Lake sediment studies. Unlike most fluvial systems, sediment load on the Niobrara is not significantly coupled with flow. The vast majority of the sediment load on this tributary is introduced during two management events each year: the spring and fall flushes of the reservoir at Spencer Dam, 40 miles upstream of the confluence of the Niobrara River and the Missouri River. Spencer Dam is shown during flush in Figure 2 and at full pool in Figure 3. Large sediment loads from the Niobrara River headwaters in the Nebraska Sandhills fill Spencer Dam's operational pool in a few months. Therefore, for the last 60 years, operators have flushed the reservoir twice annually to keep an operational pool open, making it one of the few U.S. dams that regularly flushes reservoir sediment. 
ERDC/CHL CHETN-XIV-52

July 2016

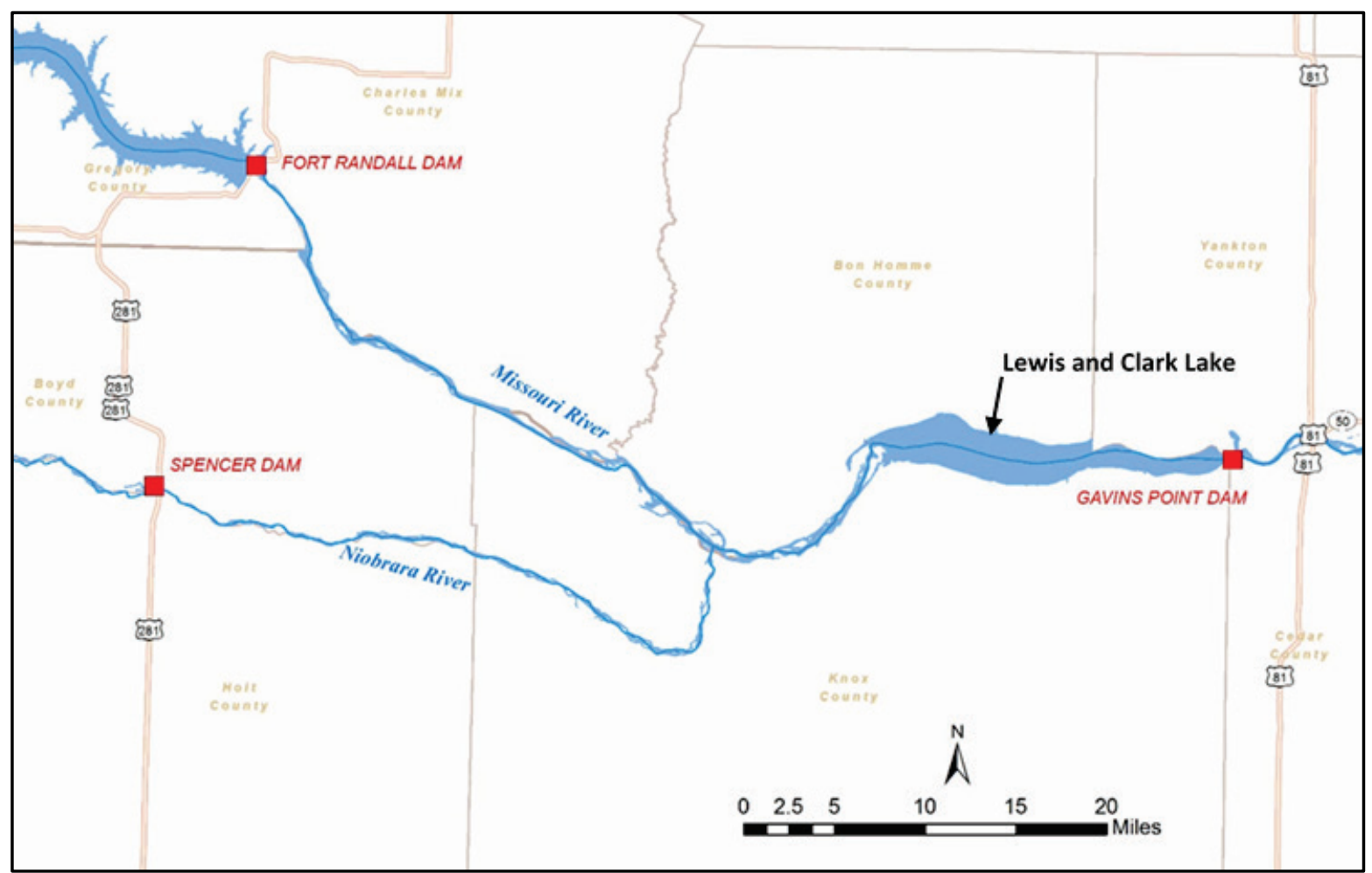

Figure 1. Spencer Dam, confluence of Niobrara River with Missouri River, and Lewis and Clark Lake.

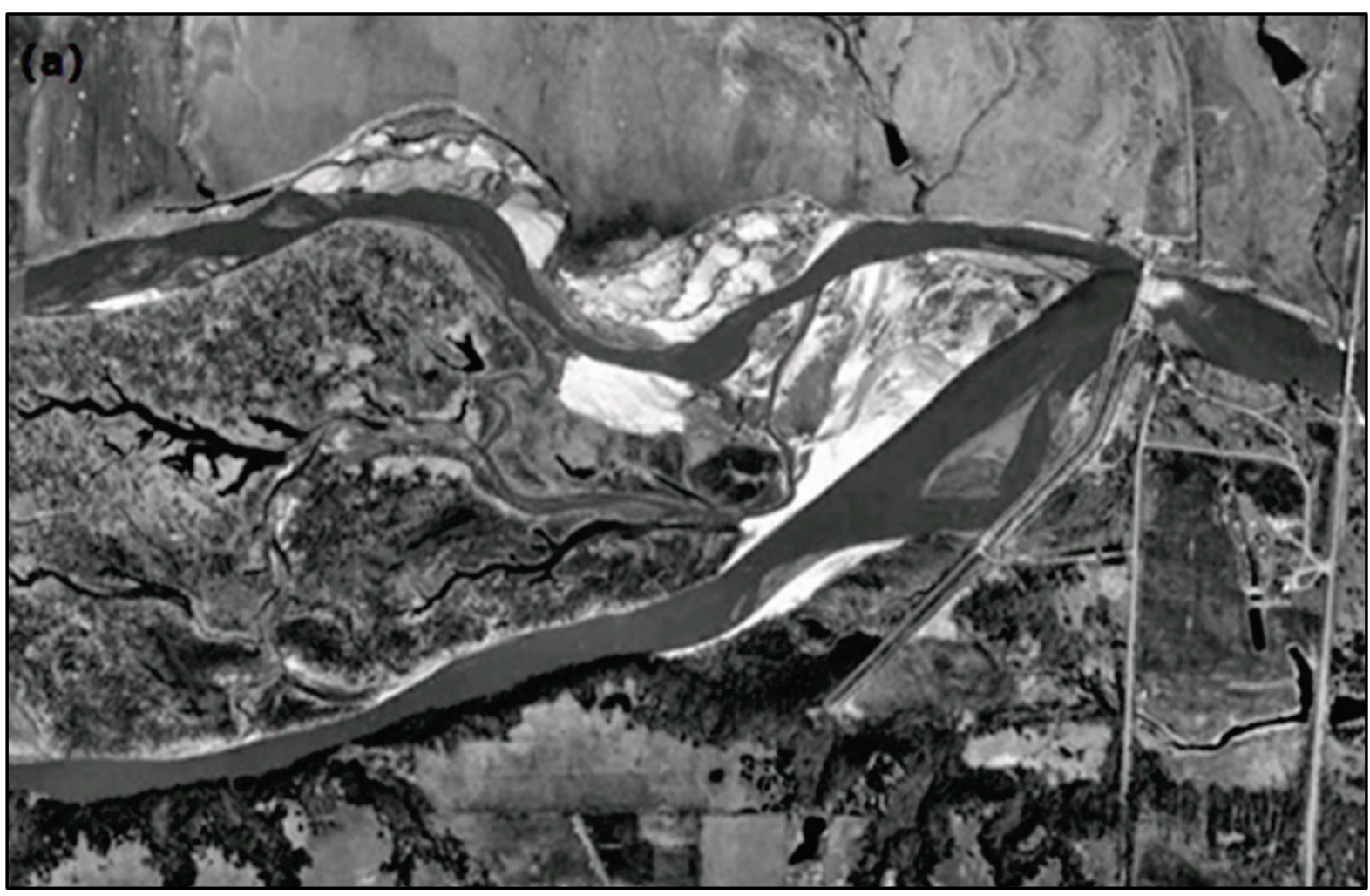

Figure 2. Spencer Dam during flush. 


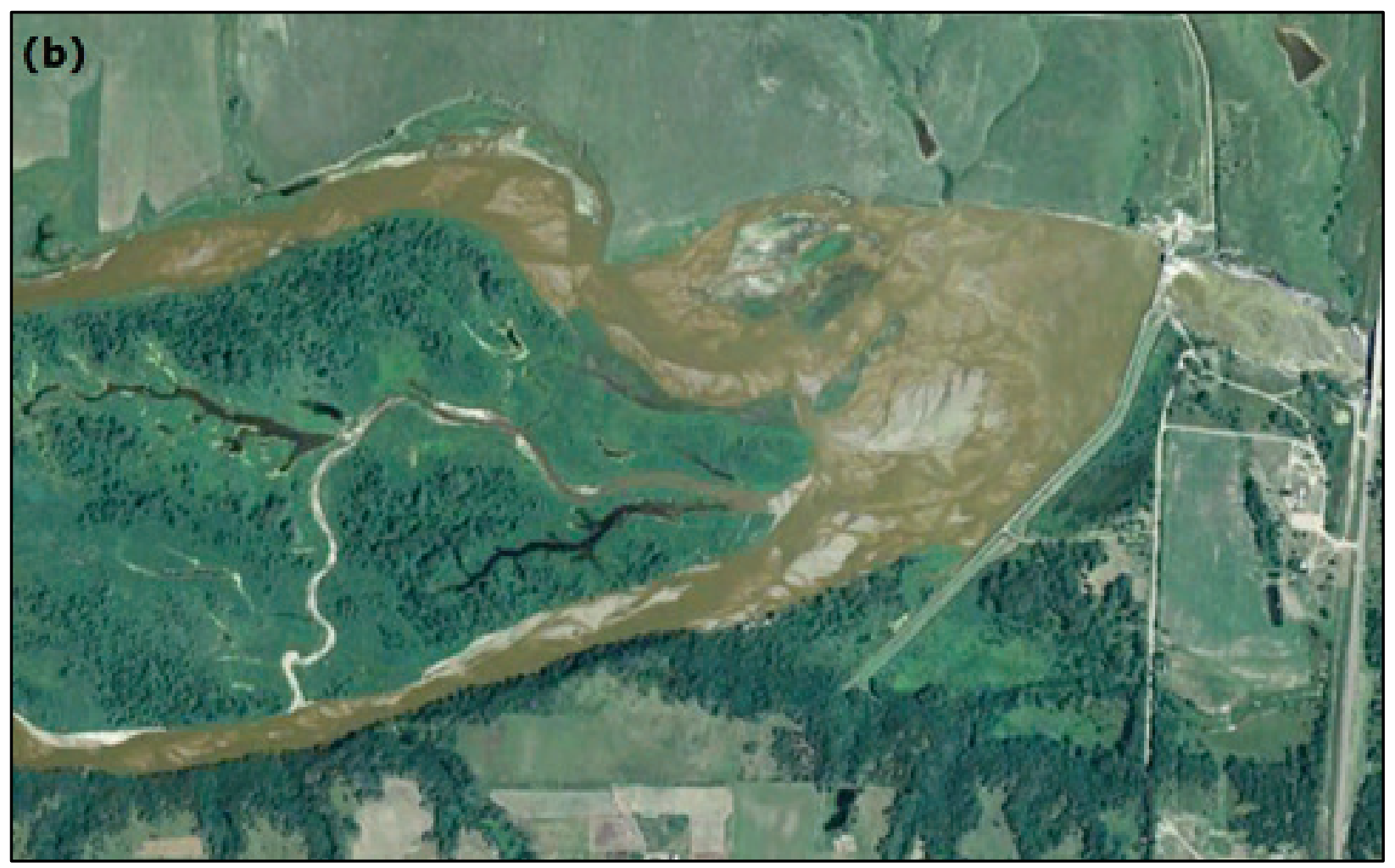

Figure 3. Spencer Dam at full pool.

Spencer Dam's predictable, semiannual flush represents a unique opportunity to capture data required to test the USACE modeling approach. The fall of 2014 presented a particularly timely opportunity because USACE canceled the Spencer Dam spring 2014 flush. Therefore, an entire year of sediment was stored in the reservoir by fall, nearly filling the pool with sediment.

The USACE Regional Sediment Management (RSM) Program (Lillycrop et al. 2011) supported a joint NWO/HEC initiative to monitor and measure one of these reservoir flushing events. The flushing event would then be modeled in the HEC-RAS sediment module to evaluate the model's effectiveness in studies like this. Additionally, a good model of the Spencer Dam/Niobrara River system would improve the existing model of Lewis and Clark Lake, which is highly sensitive to the Niobrara load. There is also a population of pallid sturgeon at the mouth of the Niobrara. A working model of this system would help managers better understand the effects of episodic sediment delivery to this region on the sturgeon with respect to how much the intervening reach captures and lags the sediment discharge over time.

MONITORING AND MEASURING THE SPENCER DAM FLUSH: An NWO, HEC, and U.S. Geological Survey (USGS) team monitored and measured the fall 2014 flush. NWO staff surveyed cross sections upstream and downstream of the dam, before and after the flush (4 weeks apart), with approximately 250 -feet (ft) cross-section spacing in the reservoir. NWO and HEC collected 17 surficial sediment samples in the reservoir before the flush. Finally, the USGS collected suspended sediment and bed material samples during the flush at three locations downstream of the dam. They collected samples every few hours during the first 2 days of the flush and then at day-to-week intervals after that. The USGS also installed a laser in situ scattering 
transmissometer (LISST) sampler downstream of the dam that estimated the suspended sediment concentration and relative proportion in each grain class.

Spencer dam operators opened the two gates $1.3 \mathrm{ft}$ and $0.8 \mathrm{ft}$ after midnight, the morning of 6 October 2014, slowly drawing the reservoir down a couple feet to minimize fish stranding. This increased the release concentration above background, but concentrations during this period were minor compared to the flush. At 0800 on October 6, Spencer Dam operators opened the two main gates, increasing the gate openings each hour until approximately 1300 when they opened the sluice gate, a fifth gate with an invert elevation $4 \mathrm{ft}$ lower than the others. Opening the main gates increased release concentrations dramatically, but opening the sluice gate pushed a head cut rapidly upstream through the reservoir sediment (Figure 4).

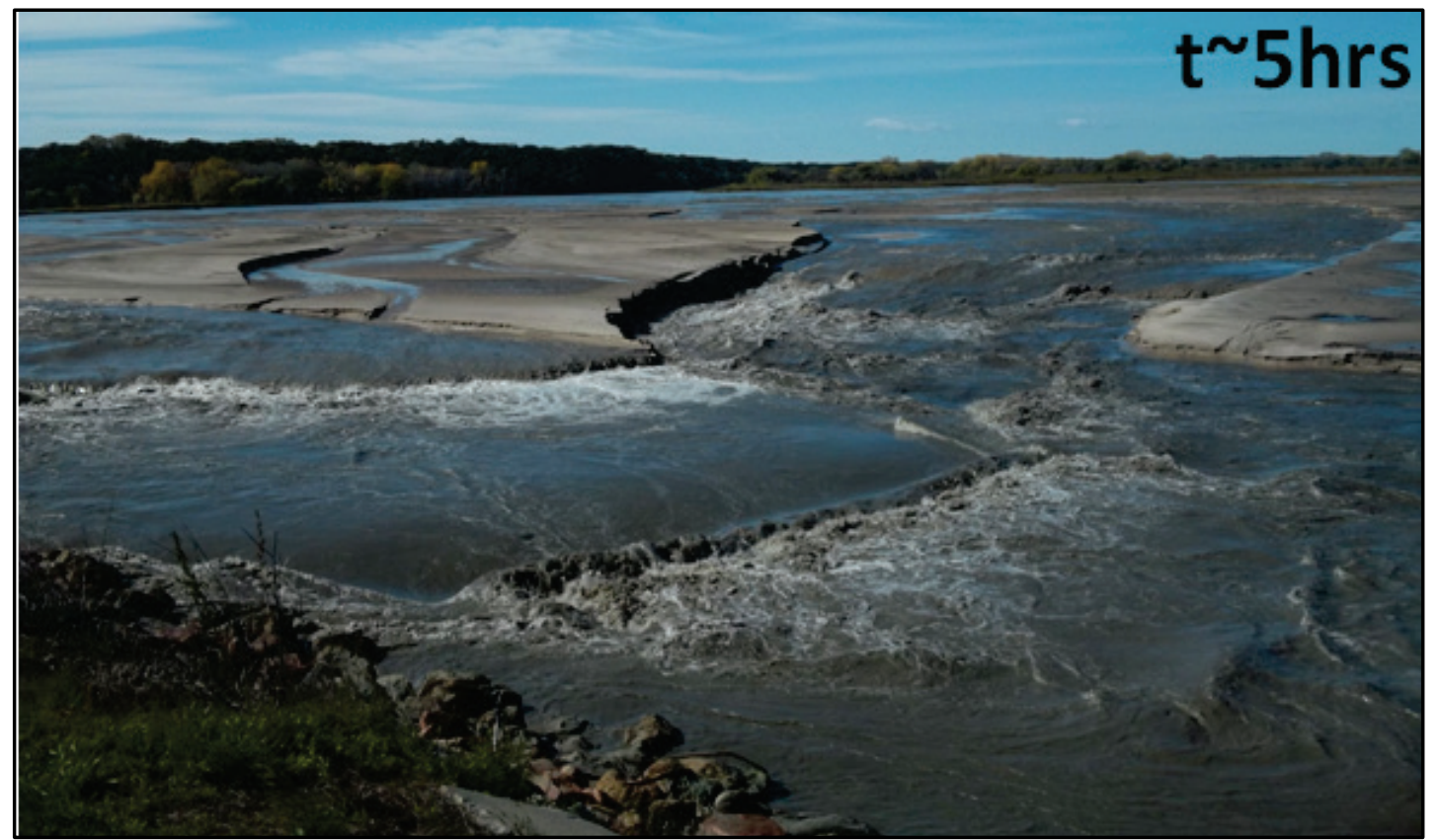

Figure 4. Opening sluice gate that was $4 \mathrm{ft}$ lower than main gates pushed a head cut rapidly upstream through reservoir sediment. Time approximately 5 hours (hr) after opening main gates.

Multiple channels eroded (Figure 5), moving sediment through the dam throughout the first day. Channel formation followed the classic channel evolution model, where a head cut quickly pushed a channel upstream at an elevation controlled by base level. But after the head cut formed the original channel, lateral processes widened it. Some of the channels encountered clay layers which slowed their incision. By the morning of October 7, the historic channel on the north end of the reservoir had incised enough to capture most of the flow, stranding the rest of the reservoir sediment in terraces (Figure 6). NWO and HEC personnel cored two of these terraces and sieved the cores to quantify their stratigraphy. These cores were mostly fine sand but had silt, clay, and even fine gravel lenses.

Release concentrations dropped after the first day when flow concentrated in the main channel. However, they remained elevated, several times base level, for most of the flush. Noticeable additional sediment evacuation was observed over the next 4 weeks. 
ERDC/CHL CHETN-XIV-52

July 2016

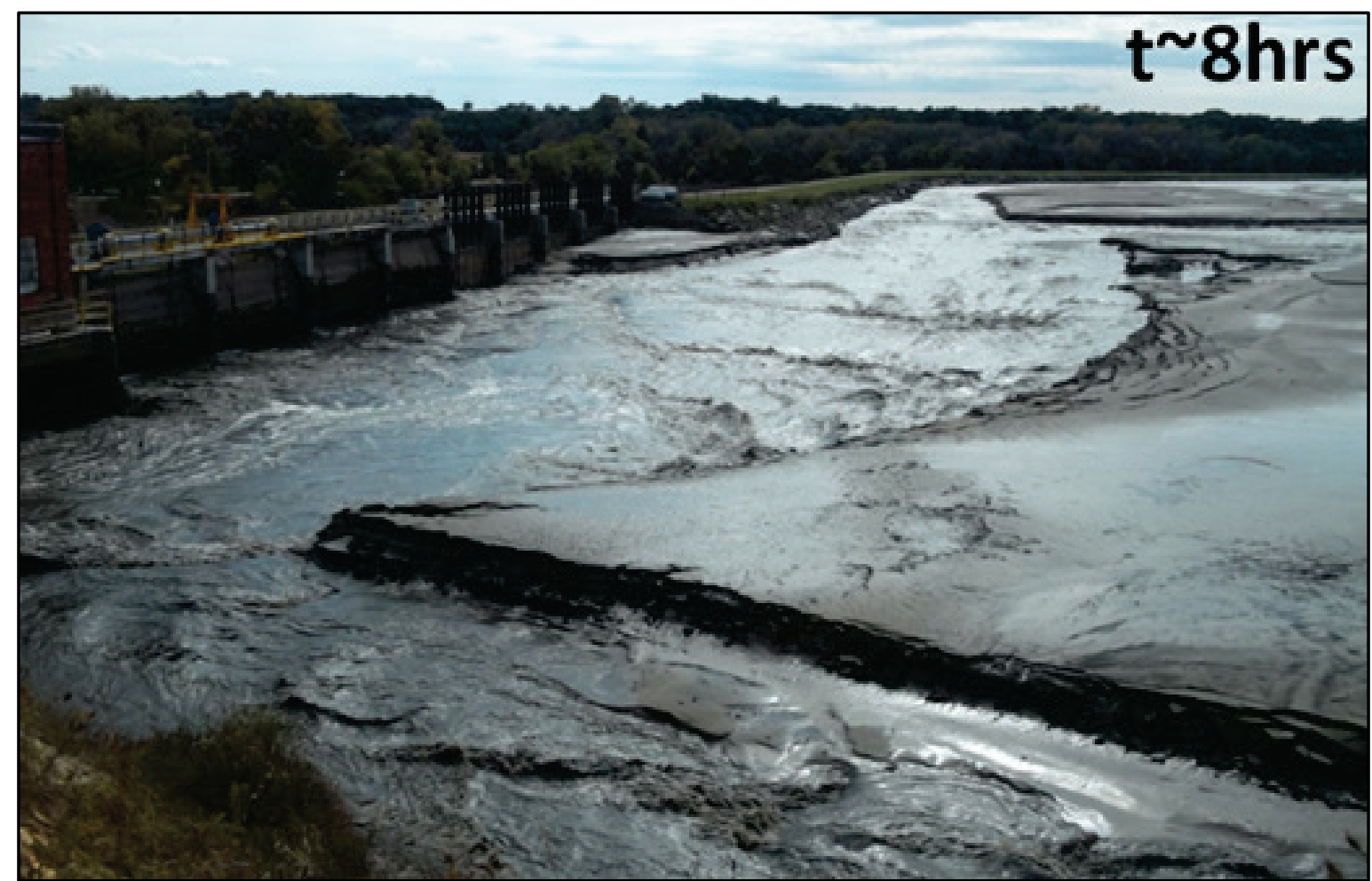

Figure 5. Multiple channels eroded throughout 6 October 2014. Time approximately 8 hours (hr) after opening main gates.

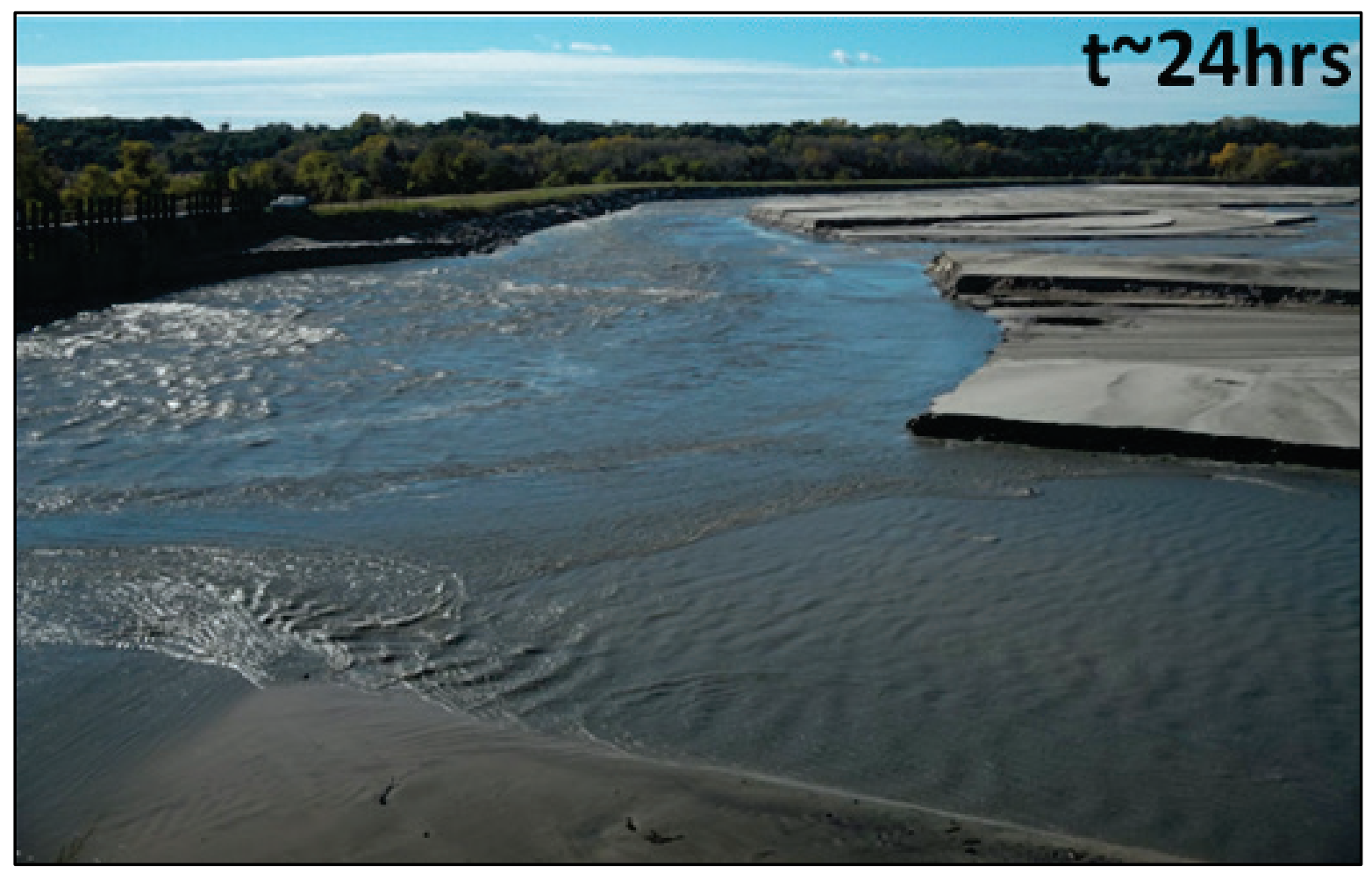

Figure 6. Historic channel incised enough to capture most of the flow, stranding the rest of the reservoir sediment in terraces. Time approximately $24 \mathrm{hr}$ after opening main gates. 
Near the end of the flush, temperatures dropped suddenly and uncharacteristically. When Spencer Reservoir filled, it immediately formed an ice cover, making the post-flush survey difficult and in places, impossible. Therefore, RSM and NWO supported a second survey, collecting cross sections at the same locations before and after the spring 2015 flush. The spring cross-sections provided a second flush data set. The missing portions after-flush cross sections from the fall 2014 flush were also approximated based on the assumption that they converged to the same basic postflush morphology. The model was constructed with the approximate fall 2014 data because it aligned with the USGS concentration data.

The fall 2014 event flushed approximately 25 million cubic feet $\left(\mathrm{Mft}^{3}\right)$ from the reservoir, depositing almost $5 \mathrm{Mft}^{3}$ in a large right channel bar in the 2,000 $\mathrm{ft}$ immediately downstream of the dam, between the dam and the USGS sampling site. Between the end of the fall 2014 flush and the beginning of the spring $2015 \mathrm{flush}, 12.3 \mathrm{Mft}^{3}$ deposited in the reservoir. Then, the spring 2015 flush (which ran for 2 weeks, half the duration of the fall flush) eroded just under $12 \mathrm{Mft}^{3}$, very close to the volume deposited since the last flush.

A sediment plume was observed at the confluence of the Niobrara River with the Missouri River 1 day into the flush (Figure 7), as the Niobrara delivered Spencer Dam sediment 40 miles to the Missouri. The plume continued along the southern bank of the Missouri River past the last observation point approximately 7 miles downstream of the Niobrara confluence. This plume appears to be mostly wash load, however, representing a small fraction of the sediment released because the total sediment concentration at the USGS gaging stations along the Niobrara River were not substantially elevated downstream of the Spencer site.

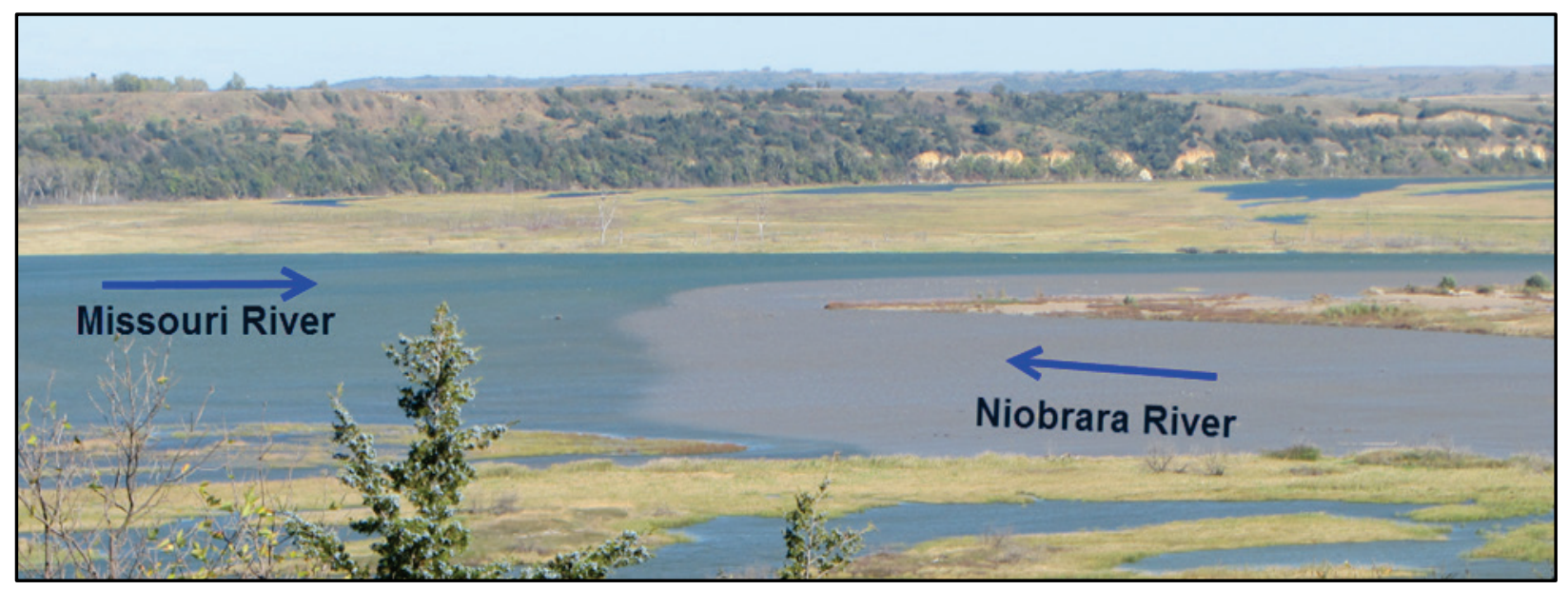

Figure 7. Sediment plume from Spencer flush on the Niobrara River entering Lew and Clark Lake on the Missouri River 1 day after the flush began. Plume was observed almost 10 miles on the Missouri River.

In contrast to the wash load, the concentration difference between the USGS sampling site just below Spencer Dam and those at Red Bird bridge (10 miles below the dam) and Verdel bridge (25 miles below the dam) suggests most of the sediment flushed from Spencer Dam was, at least temporarily, stored in the reach a few miles downstream of the dam (Figure 8). 


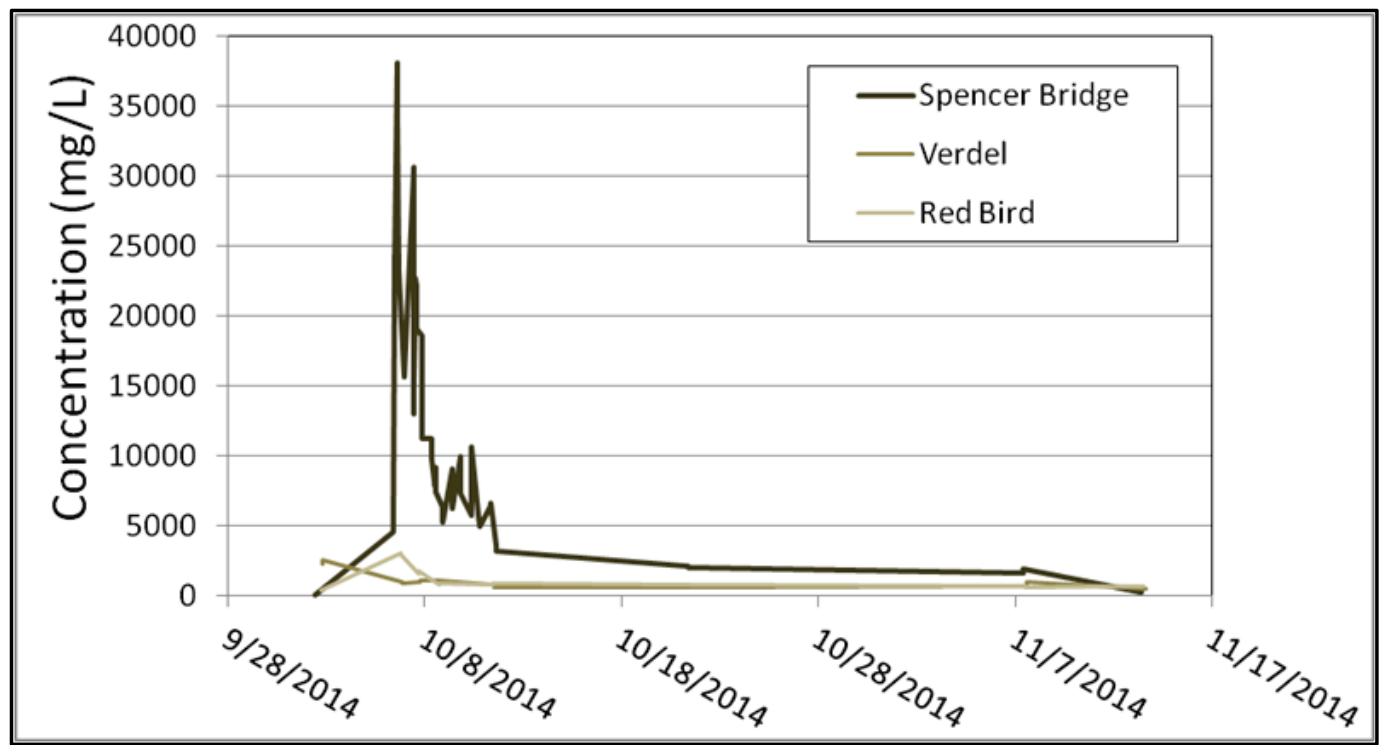

Figure 8. Concentration time series measured at three Niobrara locations from just downstream of Spencer Dam, downstream to bridges at Verdel and Red Bird. Concentration was much lower at the two downstream locations.

HEC-RAS FLUSHING MODEL: The HEC-RAS model of Spencer Dam was developed with the cross sections collected before the fall 2014 flushing event (Figure 9). The model included the new unsteady sediment transport capabilities of HEC-RAS routing water as well as sediment and represented the dam in the model as an inline structure with time-series controlled gates. The unsteady equations required 6-second $(\mathrm{sec})$ time-steps for a stable solution when the sluice gate opened, steepening the energy grade line and generating scour.

Model results were evaluated against two field metrics: (1) reservoir sediment volume change and (2) downstream concentration. The volume change calibration (Figure 10) fits the observations well in the upstream part of the reservoir where the delta is more channelized and simulates downstream deposition well. However, it underpredicts delta scour by approximately $50 \%$. One of the cross sections used to compute volume change in the delta is depicted in Figure 9. HECRAS simulated incision well, reproducing the vertical change within less than $1 \mathrm{ft}$. However, the 1D assumption in HEC-RAS cannot change cross-section nodes once the water surface elevation drops below them. It does not simulate lateral processes like undercutting or slumping. Lateral processes were observed (Figure 11) and are responsible for the wider final cross section. Lateral erosion processes of undercutting and slumping observed in Figure 11 during the flush are shown in Figure 12. HEC-RAS underpredicted scour in the delta because it did not model this widening process. This result may be improved by integrating the U.S. Department of Agriculture, Agricultural Research Service Bank Stability and Toe Erosion Model (BSTEM), the lateral process model recently added to HEC-RAS (Gibson et al. 2015) to account for widening. Results were relatively insensitive to initial sediment data (e.g., bed gradation) or parameters (e.g., transport function). 
ERDC/CHL CHETN-XIV-52

July 2016

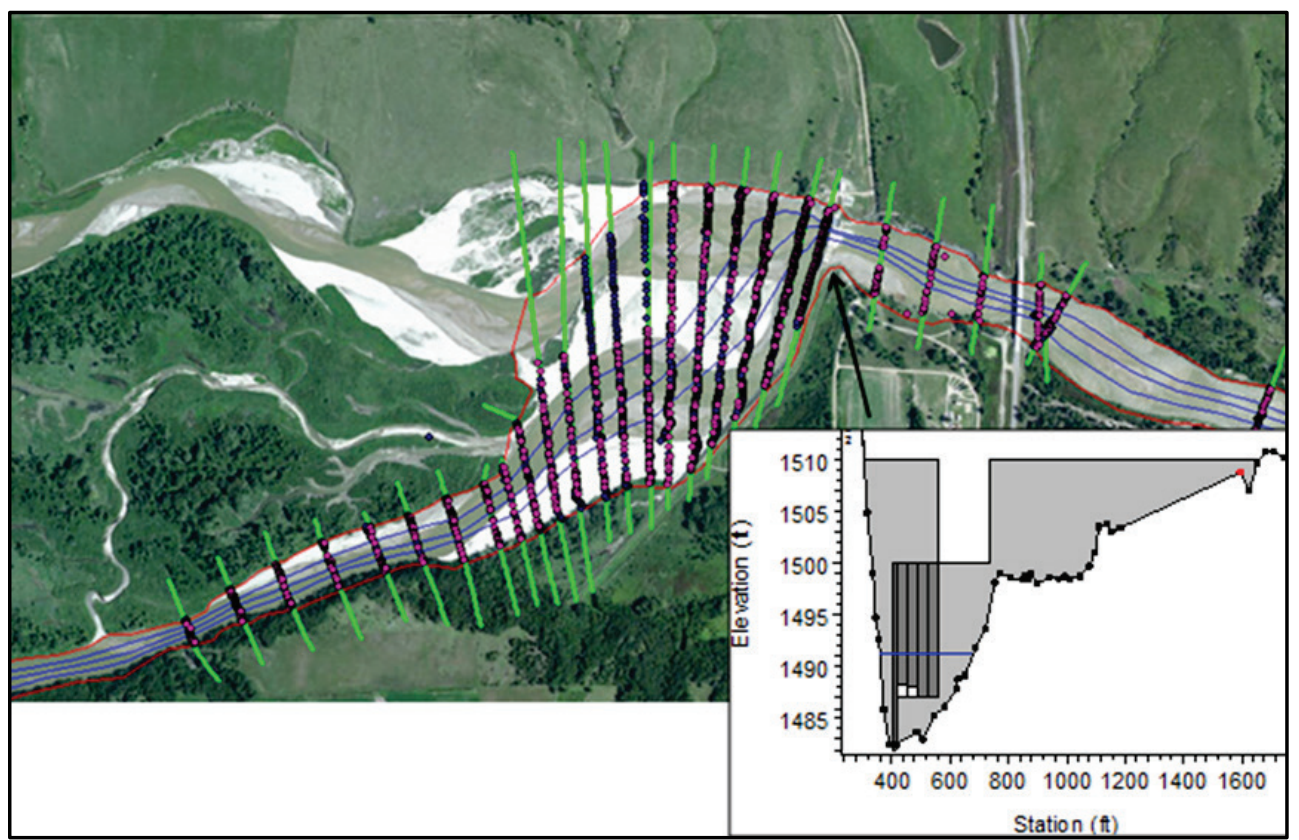

Figure 9. Cross-section location and survey points plotted with HEC-RAS cross sections, bank lines, and flow paths in HEC-geoRAS. The inline structure used to represent Spencer Dam is shown in the bottom right with the initial gate settings.

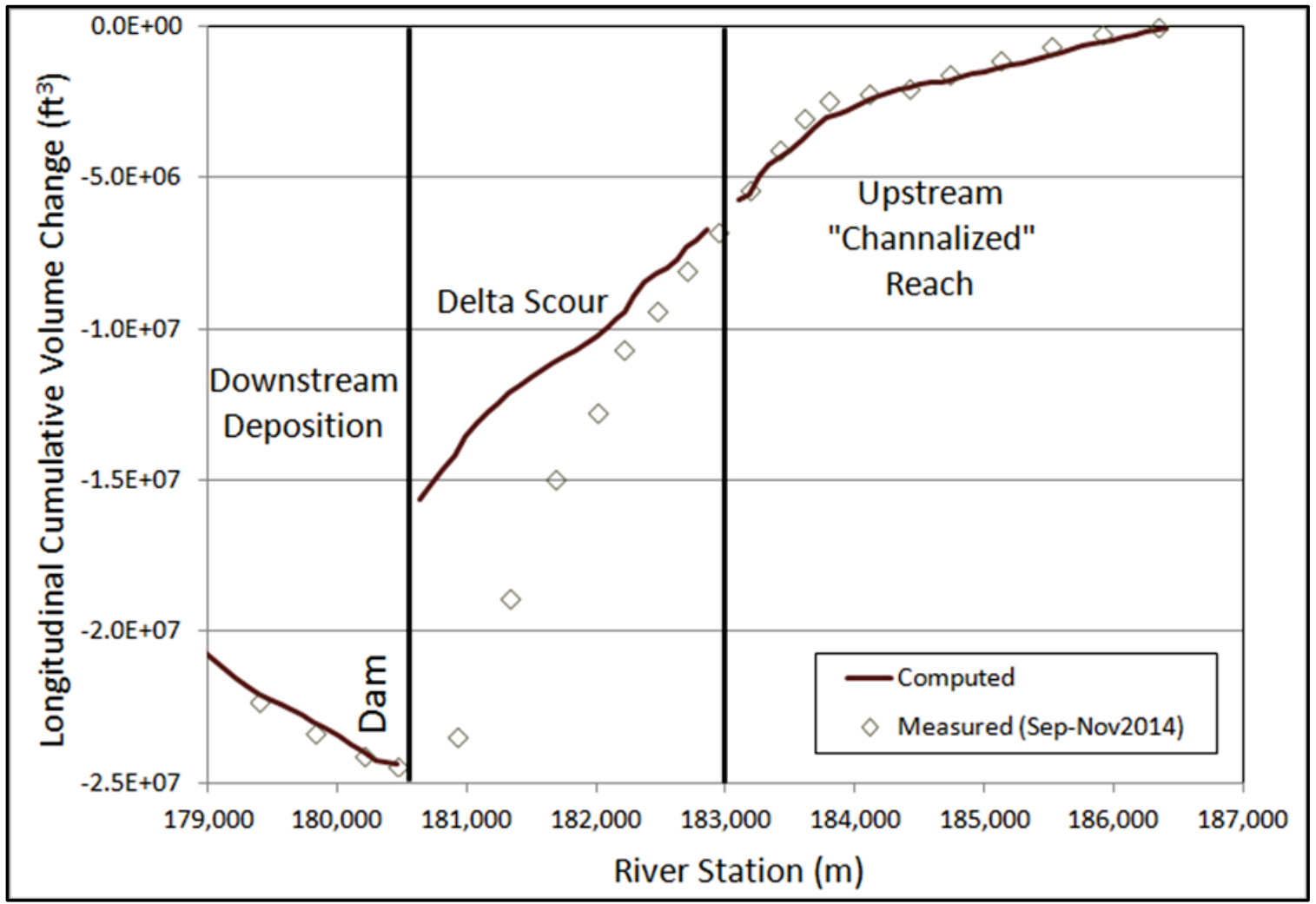

Figure 10. Observed and computed volume change computed from cross-section geometry before and after the flush, accumulated from upstream to downstream. 
ERDC/CHL CHETN-XIV-52

July 2016

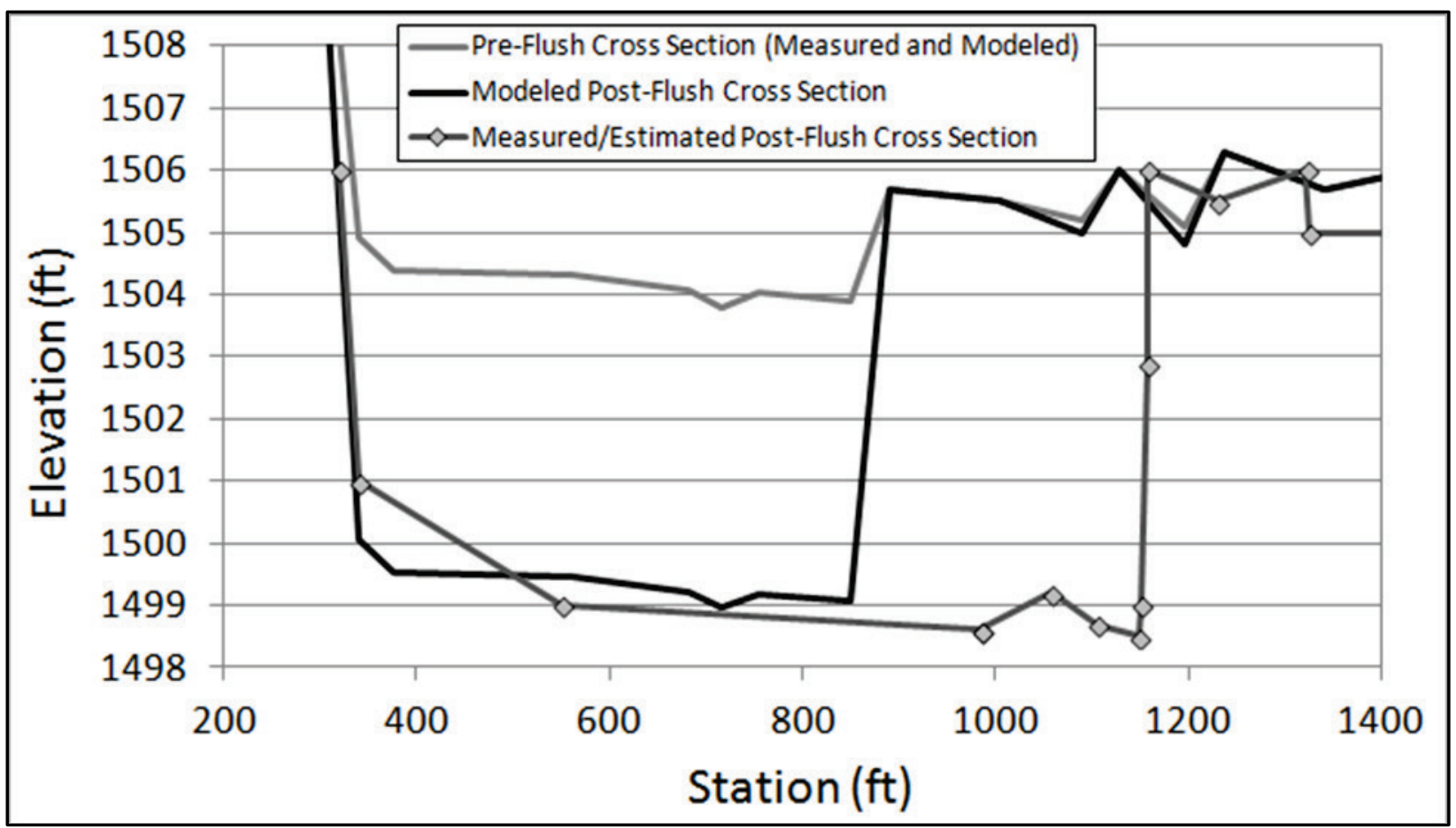

Figure 11. Computed and measured bed change at delta cross section indicated in Figure 10.

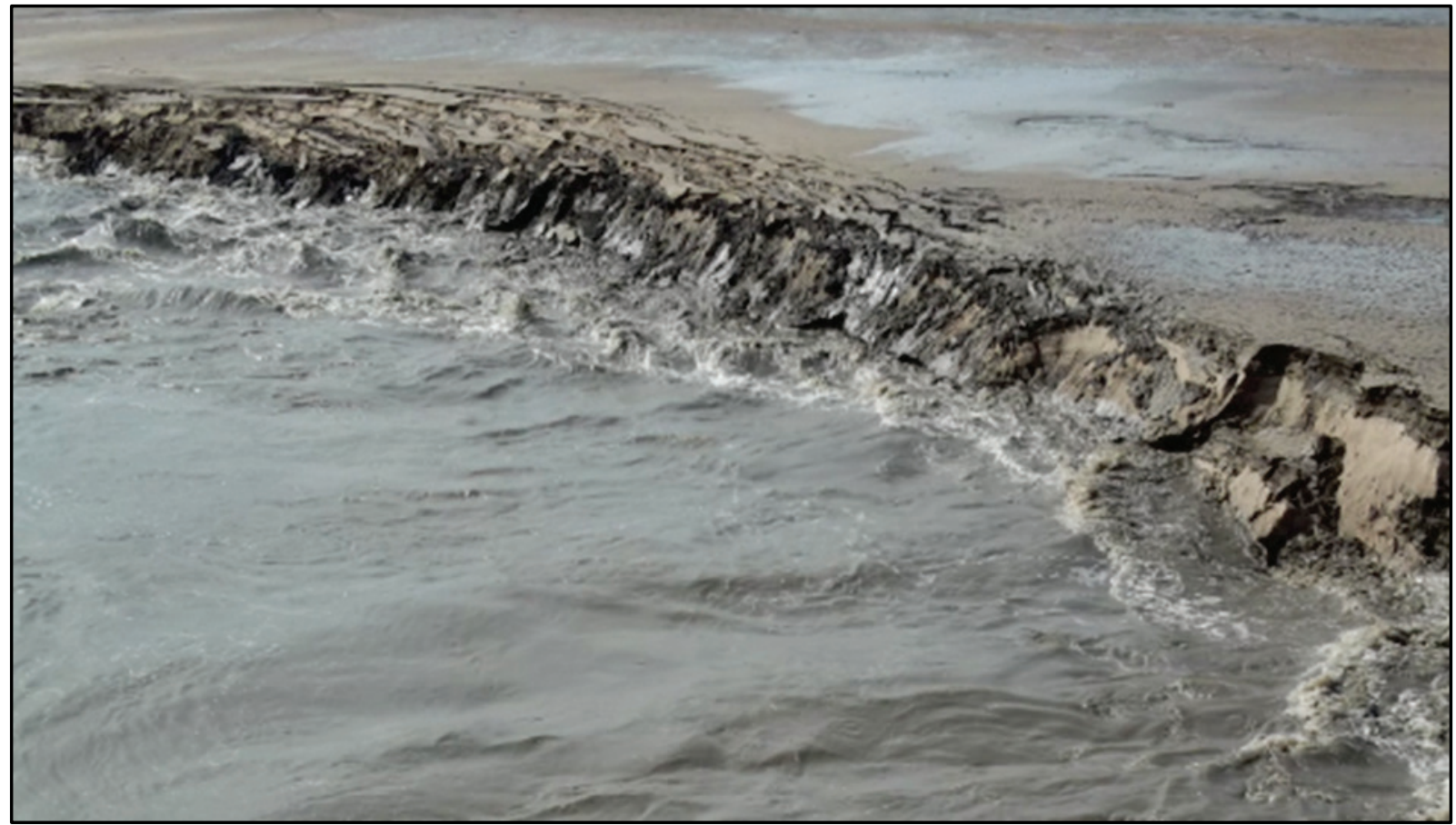

Figure 12. Lateral erosion processes (undercutting and slumping) observed during the flush in the vicinity of the cross section shown in Figure 10.

During the simulation, HEC-RAS computed sediment concentrations at the bridge downstream of Spencer Dam where the USGS measured concentration. The measured and computed concentration time series are plotted in Figure 13, demonstrating reasonable agreement. 


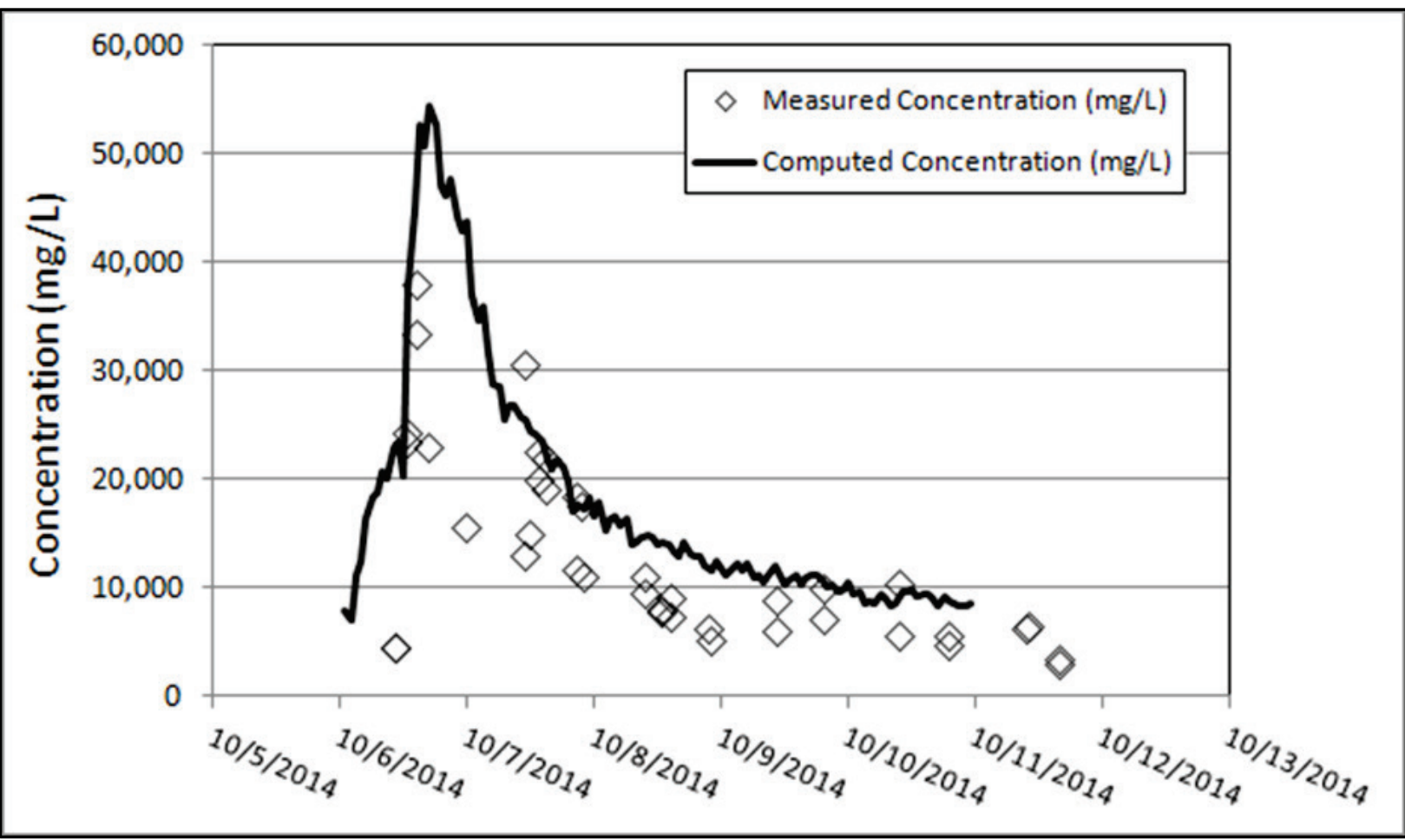

Figure 13. Measured and computed concentration at bridge 2,000 ft downstream of Spencer Dam.

LESSONS LEARNED FROM PROBLEMS ENCOUNTERED: The team encountered a number of data collection problems. These problems can be remedied in the future and are therefore considered to be Lessons Learned from Problems Encountered.

Upon initial release of the sediment-laden flushing flow, aggradation of the riverbed below the dam occurred very rapidly. The USGS LISST sampler was located in an area that did aggrade rapidly, resulting in a buried sampler head on multiple occasions over the first 2 days of the flush. Constant monitoring and adjustment of the sampling head could have resulted in a more consistent sample dataset.

As with many field-based data collection efforts, weather significantly affects data quality. Spencer Reservoir froze before NWO could collect post-flush pool geometry surveys. Cold weather is not uncommon in the upper Midwest in early November, but significant reservoir pool ice cover is rare. Surveying alternatives that can measure sub-ice reservoir bathymetry should be developed. These might include using an echo sounder through multiple holes in the ice or using a larger watercraft to safely break thin ice and survey.

CONCLUSIONS: The NWO, HEC, and the USGS measured bed change and concentration during a reservoir flushing event at Spencer Dam on the Niobrara River, Nebraska. A HEC-RAS model was developed to replicate the event. HEC-RAS computed reasonable bed change and concentration results with very little fine tuning, and the results were relatively insensitive to parameters or initial conditions. HEC-RAS 1D assumptions underpredicted scour in the reservoir 
delta. NWO and HEC are addressing this by implementing the model's lateral scour module to account for these processes observed during the flush. In addition, the team intends to expand the model to include the spring 2015 flush, which included more complete surveys but lacked the additional sediment sampling.

HEC-RAS performed well replicating the approximate magnitude and timing of the scour and downstream delivery of flushed sediment, suggesting that the model is a promising tool for evaluating flush alternatives in reservoirs without history of flushing. The Spencer Dam model will help reduce uncertainty in existing reservoir flushing models.

This NWO RSM team will continue to look for opportunities to model reservoir management strategies with HEC-RAS, including flushing, sluicing, bypassing, and possible decommissioning or dam removal.

ADDITIONAL INFORMATION: This Coastal and Hydraulics Engineering Technical Note (CHETN) was prepared as part of the Regional Sediment Management (RSM) program. This CHETN was written by Dr. Paul Boyd, USACE Omaha District (NWO), and Dr. Stanford Gibson, USACE Hydrologic Engineering Center (HEC). Additional information pertaining to the RSM program and access to this document can be found on the RSM website http://rsm.usace.army.mil.

Questions pertaining to this CHETN may be addressed to the following:

Paul M. Boyd

(USACE NWO RSM POC)

Stanford Gibson

(HEC Senior Hydraulic Engineer)

Linda S. Lillycrop

(USACE RSM Program Manager)

\section{Paul.M.Boyd@usace.army.mil}

Stanford.A.Gibson@usace.army.mil

Linda.S.Lillycrop@usace.army.mil

This CHETN should be cited as follows:

Boyd, P., and S. Gibson. 2016. Applying 1D sediment models to reservoir flushing studies: Measuring, monitoring, and modeling the Spencer Dam sediment flush with HEC-RAS. ERDC/CHL CHETN-XIV-52. Vicksburg, MS: U.S. Army Engineer Research and Development Center.

\section{REFERENCES}

Davis, C., C. Bahner, D. Eidson, and S. Gibson. 2014. Understanding reservoir sedimentation along the Rio Grande: A case study from Cochiti Dam. Proceedings, World Environmental and Water Resources Congress, pp. 2,347-2,357. doi: 10.1061/9780784413548.234 
July 2016

Gibson, S., and P. Boyd. 2014. Modeling long term alternatives for sustainable sediment management using operational sediment transport rules. In Proceedings, Reservoir Sedimentation 2014, 229-236. Edited by A. Scheiss, G. de Cesare, M. Franca, and M. Pfister. Saussane, Switzerland: Special Session on Reservoir Sedimentation of the Seventh International Conference on Fluvial Hydraulics (River Flow 2014) IAHR Committee on Fluvial Hydraulics.

Gibson, S., A. Simon, E. Langendoen, N. Bankhead, and J. Shelley. 2015. A physically-based channelmodeling framework integrating HEC-RAS sediment transport capabilities and the USDA-ARS Bank-Stability and Toe-Erosion model (BSTEM). In Proceedings, SedHyd 2015.Reno, NV: Joint Federal Interagency Conference on Sedimentation and Hydrologic Modeling.

Lillycrop, L. S., J. McCormick, L. Parson, and M. Chasten. 2011. Adaptive management through regional sediment management. In Proceedings of the Western Dredging Association (WEDA XXXI) Technical Conference and Texas A\&M University (TAMU 42) Dredging Seminar, 178-187. Nashville, TN.

Shelley, J., and S. Gibson. 2015. Modeling bed degradation of a large, sand-bed river with in-channel mining with HEC-RAS 5.0. In Proceedings, SedHyd 2015. Reno, NV: Joint Federal Interagency Conference on Sedimentation and Hydrologic Modeling.

NOTE: The contents of this technical note are not to be used for advertising, publication, or promotional purposes. Citation of trade names does not constitute an official endorsement or approval of the use of such products. 